УДК 534.833

\title{
СИНТЕЗ ШИРОКОСМУГОВИХ \\ АКТИВНИХ ВІБРОЗАХИСНИХ ПРИСТРОЇВ ДЛЯ ВАНТАЖОПІДЙОМНИХ КРАНІВ 3 МЕХАТРОННИМИ СИСТЕМАМИ УПРАВЛІННЯ ДЕМПФУВАННЯМ
}

( В. С. Ловейкін, д.т.н., професор, Ю. В. Човнюк, к.т.н., доцент, Національний університет біоресурсів і природокористування України, Київ, Україна, К. І. Почка, к.т.н., доцент, Київський національний університет будівництва і архітектури, Київ, Україна

На основе динамического анализа широкополосных активных виброзащитных систем с управляемым демпфированием предложены мехатронные системы (МС) управления последними для грузоподъёмных кранов.

Based on the dynamic analysis of the broadband active vibroprotective systems with controlled damping the control mechatronic systems over damping have been offered for cargo cranes.

\section{Постановка проблеми}

До захисту різноманітних об'єктів, зокрема, вантажопідйомних кранів, від шкідливого впливу вібрацій застосовуються активні віброзахисні системи (ABC), що є системами автоматичного управління коливаннями. Зазвичай пропонуються схеми АBC, які реалізують принцип широкосмугової компенсації сил, що передаються на основу. АВС цього типу дозволяють забезпечити ефективний віброзахист на частотах за першим власним резонансом об'єкту (вантажопідйомного крану). Для зменшення амплітуд резонансних коливань та розширення частотного діапазону віброзахисту у широкосмугові компенсаційні АВC вводять кероване демпфування. При цьому не знижуються резонансні коливання об'єкту віброзахисту. Зменшити амплітуду резонансних коливань можна, формуючи у певних частотних діапазонах керовані впливи у протифазі зі швидкістю надопорних перерізів віброактивного об'єкту (вантажопідйомного крану).

Для мостових кранів це еквівалентно введенню у систему на резонансних частотах керованого демпфування додатково до зазвичай малого конструкційного демпфування у пасивних амортизаторах та матеріалі балки.

Використання сучасних мехатронних систем (МС) управління ABC передбачає введення попередніх підсилювачів з фільтрами верхніх частот, ланцюгів широкосмугової компенсації, контурів керованого демпфування, котрі 
забезпечують додаткове зниження віброактивності на резонансних частотах власних коливань мостового крану.

Кероване демпфування вводять за допомогою оптимально налаштованих вузькосмугових фільтрів, які забезпечують максимальне зниження амплітуд резонансних коливань та несуттєво спотворюють амплітудно-фазочастотні (АФЧ) характеристики основних каналів широкосмугової компенсації.

Стійкість АВС з мехатронними системами управління демпфуванням за наявності високочастотних резонансів опорної балки мостового крану та каналів керування вимагає подальшого дослідження, що й зроблено у даній роботі.

\section{Аналіз попередніх досліджень}

Активні віброзахисні системи $(\mathrm{ABC}) €$ по суті системами автоматичного управління коливаннями й запропоновані у [1]. У [2] запропоновані схеми ABC, які реалізують принципи широкосмугової компенсації сил, що передаються на основу. $\mathrm{ABC}$ цього типу дозволяють забезпечити ефективний віброзахист на частотах за першим власним резонансом об'єкту. Для зменшення амплітуд резонансних коливань та розширення частотного діапазону віброзахисту у роботі [3] запропоновано у широкосмугові компенсаційні АВС ввести кероване демпфування [4].

У роботі [5] розроблена методика та отримані формули для вибору параметрів широко- смугових $\mathrm{ABC} 3$ керованим демпфуванням. Автори цієї роботи досліджують деякі питання стійкості та ефективності цих схем ABC і проводять зіставлення теоретичних та експериментальних результатів.

На рис. 1 показана АВС двоопорної пружної балки (мостового крану). Паралельно пасивним амортизатором, які мають жорсткості $\mathrm{c}_{1,2}$ і коефіцієнти демпфування $\mathrm{h}_{1,2}$, встановлені активні виконавчі елементи (наприклад, електромеханічні вібратори), котрі формують керуючі впливи $\mathrm{f}_{1}^{\mathrm{a}}$ та $\mathrm{f}_{2}^{\mathrm{a}}$ за сигналами з датчиків сили, які передаються на основу [2]. Таким чином, здійснюється широкосмугова компенсація сил, що передаються через пасивні амортизатори. При цьому не знижуються резонансні коливання об'єкту віброзахисту. Зменшити амплітуду резонансних коливань можна, формуючи у певних частотних діапазонах керуючі впливи у протифазі зі швидкістю надопорних перерізів віброактивного об'єкту.

Це еквівалентно введенню у систему на резонансних частотах керованого демпфування додатково до зазвичай малого конструкційного демпфування у пасивних амортизаторах та матеріалі балки (мостового крану, зокрема).

Канали керування АBC (рис. 1) складаються 3 передавальних функцій $W_{1}^{i}(i=1,2)$ попередніх підсилювачів 3 фільтрами верхніх частот [2], ланцюгів широкосмугової компенсації $W_{20}^{i}(i=1,2)$ та передавальних функцій $W_{2 j}^{i}(i=1,2$; 


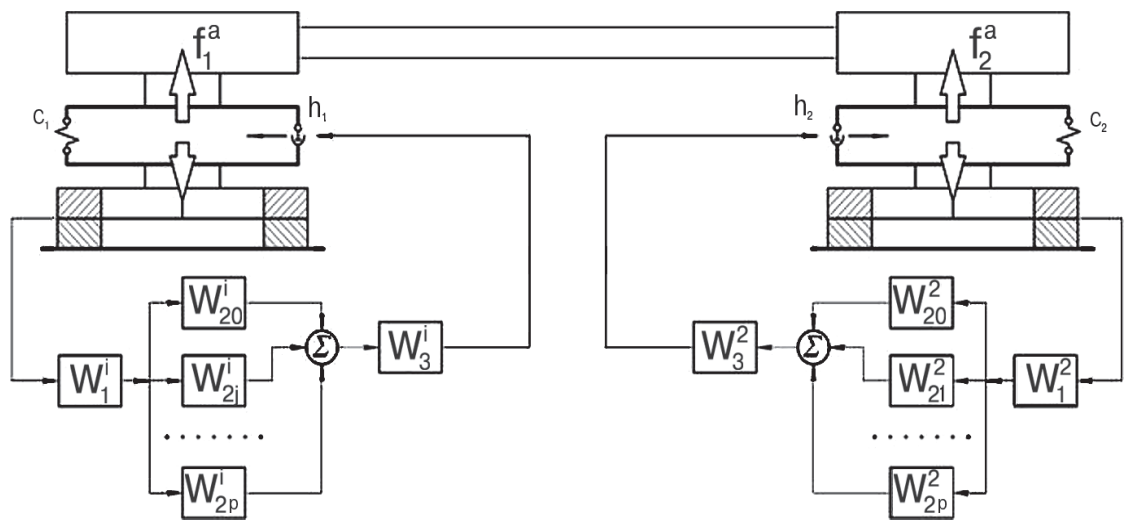

Рис. 1. Схема активної віброзахисної системи двоопорної пружної балки (мостового крану)

j = $1 \div$ р) контурів керованого демпфування, котрі забезпечують додаткове зниження віброактивності на р резонансних частотах власних коливань об'єкту (мостового крану). Вказані канали по суті утворюють інфраструктуру МС управління демпфуванням коливань балки мостового крану.

Кероване демпфування вводять за допомогою оптимально налаштованих [3, 5] вузькосмугових фільтрів, що забезпечують максимальне зниження амплітуд резонансних коливань та несуттєво спотворюють АФЧ характеристики основних каналів широкосмугової компенсації. Передавальні функції $\mathrm{W}_{3}^{\mathrm{i}}(\mathrm{i}=1,2)$ описують характеристики таких динамічних підсистем каналів зворотнього зв'язку, як виконавчі елементи, обмежуючі фільтри, пружні з'єднуючі пристрої і т. д. За правилами перетворення структурних схем [7] визначимо загальний вираз для передавальної функції $\mathrm{W}_{\Sigma}^{\mathrm{i}}$ каналу управління:

$$
\begin{aligned}
& W_{\Sigma}^{i}=W_{1}^{i} \cdot\left(\sum_{j=0}^{1} W_{2 j}^{i}\right) \cdot W_{3}^{i}, \\
& i=\overline{(1,2)} .
\end{aligned}
$$

За допомогою методу заданих форм [6] запишемо рівняння усталеного стану $\mathrm{ABC}$ :

$$
\left\{\begin{array}{l}
q_{n} \cdot\left(s^{2}+\lambda_{n}^{*} \cdot \omega_{n} \cdot s+\omega_{n}^{2}\right)= \\
=\frac{1}{m_{n}} \cdot Q_{n} ; \\
Q_{n}=\sum_{i=1}^{2}\left(f_{i}^{a}-h_{i} \cdot s \cdot y_{i}\right) \cdot \varphi_{n i}+ \\
+f^{B} \cdot \varphi_{n B} ; \\
f_{i}^{a}=W_{\Sigma}^{i} \cdot\left(h_{i} \cdot s+C_{i}\right) \cdot y_{i} ; \\
y_{i}=\sum_{n=1}^{1} g_{n} \cdot \varphi_{n i} ; n=\overline{(1, l)} ; \\
i=\overline{(1,2)} ; s=d / d t
\end{array}\right.
$$

де $q_{n}, \omega_{n}, \lambda_{n}^{*}, m_{n}$ та $Q_{n}$ - узагальнена координата, власна частота, затухання, узагальнена маса та узагальнена сила n-го тону власних коливань балки мостового крану; I - число врахованих тонів; $\varphi_{n i}-$ значення форми 
n-го тону у точці кріплення i-ї опори; $\varphi_{\mathrm{nB}}-$ значення форми n-го тону у точці прикладання сили зовнішнього збурення $\mathrm{fB}$ (рис. 1). Число I враховуваних у розрахунках тонів власних коливань об'єкту віброзахисту визначається частотним діапазоном роботи $\mathrm{ABC}$. Значення $\omega_{\mathrm{n}}$, $\mathrm{m}_{\mathrm{n}}(\mathrm{n}=1, \mathrm{l})$ та $\varphi_{\mathrm{ni}}, \varphi_{\mathrm{nB}}(\mathrm{n}=1, \mathrm{l}$; $\mathrm{i}=1,2)$ розраховані за допомогою функцій А. Н. Крилова [6] для симетричної пружної двоопорної балки з масами і моментами інерції на її кінцях (рис. 1).

Необхідно дослідити стійкість $\mathrm{ABC}$ із врахуванням високочастотних резонансів балки та МC управління демпфуванням.

\section{Мета роботи}

Полягає у встановленні умов стійкості активної віброзахисної системи з мехатронною системою керуванням демпфуванням для балок мостових кранів при врахуванні наявних високочастотних резонансів (цієї балки).

\section{Результати проведеного дослідження}

Дослідимо стійкість АBC із врахуванням високочастотних резонансів балки і каналів управління. Будемо вважати канали МС управління кожної з опор балки мостового крану однаковими. Елемент управління $\mathrm{W}_{3}$, що має високочастотний резонанс, поданий фільтром нижніх частот другого порядку з передавальною функцією у вигляді:

$$
W_{3}=\frac{r_{3}^{2}}{s^{2}+\left(r_{3} / Q_{3}\right) \cdot s+r_{3}^{2}},
$$

де $r_{3}$ та $Q_{3}$ - резонансна частота та добротність фільтру низьких частот (ФНЧ). До такого виду можна привести (при врахуванні тільки одного найнижчого тону власних коливань) динамічні характеристики пружно підвішених реактивних мас електромеханічних вібраторів, пружних з'єднувальних пристроїв тощо.

Дослідження стійкості АВС виконано шляхом аналізу розміщення на комплексній площині кореневих годографів [7] багатовимірної (MC) автоматичного управління (рис. 1) демпфуванням коливань балки мостового крану. У розрахунках враховувались перші п'ять тонів власних коливань балки. Всі характерні частоти електромеханічної системи АВС (власні частоти пружного об'єкту та ланцюгів каналів управління) віднесені до першої власної частоти коливань балки на пасивних амортизаторах. Кожній точці годографа відповідає поточне значення параметру $\mathrm{k}_{2}$ (безрозмірного коефіцієнту підсилення каналу широкосмугової компенсації). Значення параметру $\mathrm{k}_{2}^{*}$, за яких комплексні власні частоти $\left(\alpha=\delta+\mathrm{i} \cdot \omega, \mathrm{i}^{2}=-1\right)$ покинуть ліву півплощину, $є$ граничними за умовою стійкості. Ординати точок перетину годографів з уявною віссю визначають частоти $\omega_{\mathrm{B}}$ самозбудження ABC.

На рис. 2, а показані кореневі годографи $\mathrm{ABC}$, яка реалізує тільки широкосмугову компенсацію $\left(\mathrm{W}_{2 \mathrm{j}}=0 ; \mathrm{j}=1, \mathrm{p}\right)$, без врахування високочастотних резонансів каналу управління МC 
$\left(\mathrm{W}_{3}=1\right)$. Самозбудження відбувається на низьких частотах (нижня гілка годографу, яка відповідає першому тону власних коливань, перетинає уявну вісь раніше інших гілок). Граничний коефіцієнт підсилення $\mathrm{k}_{2}^{*}=0,72$ та частота самозбудження $\omega$ В відповідають значенням, котрі можуть бути отримані за допомогою оцінок, запропонованих у роботі [2], де об'єкт розглядається як абсолютно тверде тіло. На рис. 2, б приведені годографи тієї ж ABC, але 3 ланцюгом $\mathrm{W}_{3}(3)$, який враховує високочастотний резонанс каналу управління МС. При цьому резонансна частота $r_{3}=15$ близька до частоти п'ятого тону власних коливань балки $\left(\omega_{5}=\right.$ $=13,6) .3$ рис. 2 , б випливає, що у такій системі самозбудження виникає на частоті, що практично співпадає 3 частотою найбільш близького тону власних пружних коливань балки. При цьому знижується ефективність $A B C$ за рахунок зменшення гранично припустимого (за умовами стійкості) значення коефіцієнту підсилення $\mathrm{k}_{2}$ $\left(k_{2}^{*}=0,45\right.$ замість $k_{2}^{*}=0,72-$ puc. 2, a).
Аналіз серії аналогічних годографів дозволяє побудувати області стійкості $\mathrm{ABC}$ (рис. 3, а) у площині коефіцієнта підсилення $\mathrm{k}_{2}$ та величини відносної розбіжності $\beta=r_{3} / \omega_{5}$, яка характеризує близькість резонансних частот управління і власних коливань об'єкту. Тут по вісі ординат відкладені також значення відповідних асимптотичних оцінок ефективності широкосмугового віброзахисту, що обчислюються за формулою [2] $B=20 \lg \left\{1 /\left(1-k_{2}\right)\right\} \partial Б$. Границі областей стійкості та відповідні ім частоти самозбудження $\omega_{\mathrm{B}}$ (рис. 3) розраховані для різних значень добротності $Q_{3}$. При перетині отриманих областей стійкості прямою 3 рівнем $\mathrm{k}_{2}=0,72$ (граничне значення коефіцієнту компенсації для абсолютно жорсткого об'єкту) частота самозбудження стрибком змінюється й переходить з частоти, розрахованої для АВС абсолютно жорсткого об'єкту [2], на частоту, близьку до згинного резонансу коливань балки. При подальшому збільшенні розбіжності $\beta$ (рис. 3 , б) частота самозбудження $\mathrm{ABC}$ також стрибком переходить назад з верхніх час-

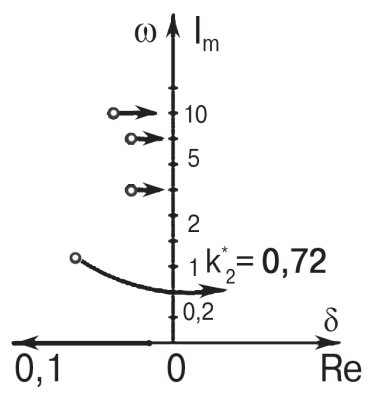

a

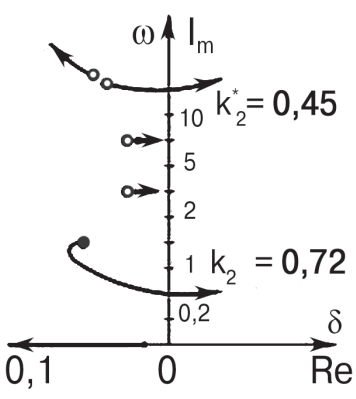

б

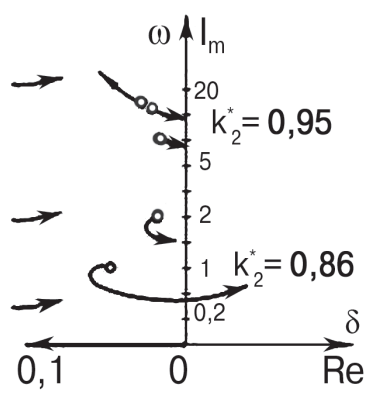

B

Рис. 2. Кореневі годографи АВС з МС управління демпфуванням 
тот на нижчі. Таким чином, причиною високочастотного самозбудження у широкосмугових ABC (виявленого при проведенні експериментальних досліджень АВС двоопорної пружної балки мостового крану) є близьке розміщення резонансів МС управління демпфуванням, які мають досить високу добротність (наприклад, для рис. 3 $\left.Q_{3} \geq 5\right)$, і власних частот пружних коливань віброактивного об'єкту.

Досліджуючи поведінку кореневих годографів (рис. 2, б, в) та частот самозбудження (рис. 3, б), можна зробити припущення, що для високочастотного збудження ABC визначальним $є$ взаємодія тільки одного з тонів власних коливань балки мостового крану з каналом МС управління. При втраті стійкості демпфування $\delta$ на частоті $\omega$, близькій до власної частоти коливань k-го тону, стає рівним нулю, і тоді стійкість АВС визначається коливаннями об'єкту саме за k-м тоном (2): $\mathrm{y}_{\mathrm{i}}=\sum_{\mathrm{n}=1}^{\mathrm{l}} \mathrm{q}_{\mathrm{n}} \cdot \varphi_{\mathrm{ni}} \approx \mathrm{q}_{\mathrm{k}} \cdot \varphi_{\mathrm{ki}}$. При цьому характеристичне рівняння системи (2) має вид:

$\mathrm{D}(\mathrm{s})=\left(\mathrm{s}^{2}+\lambda_{\mathrm{k}}^{*} \cdot \omega_{\mathrm{k}} \cdot \mathrm{s}+\omega_{\mathrm{k}}^{2}\right)-\frac{1}{\mathrm{~m}_{\mathrm{k}}}$.

$\cdot \sum_{i=1}^{2}\left(-h_{i} \cdot s+\left(h_{i} \cdot s+C_{i}\right) \cdot W_{\Sigma i}\right) \cdot \varphi_{k i}^{2} ;$

$i=\overline{(1,2)}$.

Для перевірки правильності зробленого припущення проведена серія розрахунків стійкості $\mathrm{ABC}$ із врахуванням п'яти власних тонів коливань балки (за си- стемою рівнянь (2)) та з врахуванням тільки одного «небезпечного» тону, найбільш близького до високочастотних резонансів каналів МС управління (за характеристичним рівнянням (4)). Практично точне співпадіння результатів дозволяє зробити висновок про можливість проведення інженерної оцінки граничних коефіцієнтів підсилення й частот самозбудження ABC пружних об'єктів шляхом дослідження окремих підсистем невисокої розмірності за спрощеним характеристичним рівнянням.

у тих випадках, коли не вдається уникнути високочастотного самозбудження ABC конструктивними засобами (мехатроніки), наприклад, рознесенням резонансних частот об'єкту та МС управління, зменшенням добротності резонансних ланцюгів зворотних зв'язків тощо, - існує можливість попередити самозбудження (й тим самим підвищити ефективність $\mathrm{ABC})$ за допомогою керованого демпфування пружних коливань балки мостового крану. На рис. 2, в показані кореневі годографи широкосмугової АВС 3 демпфуванням «небезпечного» тону $\left(\omega_{5}=13,6\right)$, а також нижчого $\left(\omega_{1}=1\right)$ та першого згинного $\left(\omega_{3}=3,2\right)$ тону власних коливань балки. 3 введенням керованого демпфування можливість високочастотного збудження виключена: нижня гілка годографа (рис. 2, в), яка відповідає коливанням за нижнім тоном, першою перетинає уявну вісь.

На рис. 2, в у порівнянні 3 рис. 2, б з'явились траєкторії коренів, що відповідають ком- 


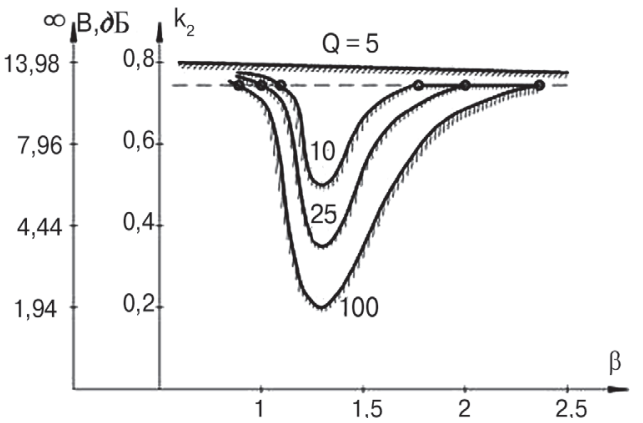

a

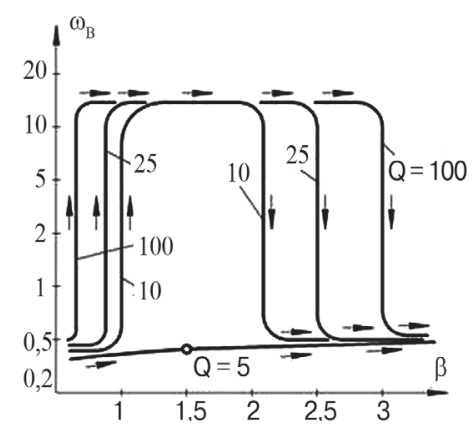

6

Рис. 3. Границі областей стійкості (а) та частоти самозбудження (б)

плексним частотам контурів керованого демпфування першого $\left(\mathrm{W}_{21}\right)$, третього $\left(\mathrm{W}_{23}\right)$ та п'ятого $\left(\mathrm{W}_{25}\right)$ тонів власних коливань. Кероване демпфування ніби зсуває «небезпечні» гілки кореневих годографів (рис. 2, в) від уявної вісі площини комплексних частот, тобто підвищує запаси стійкості, дозволяючи за рахунок цього збільшити припустиме значення коефіцієнту широкосмугової компенсації $\mathrm{k}_{2}$ [3] $\left(k_{2}^{*}=0,86\right.$ на рис. 2, в замість $\mathrm{k}_{2}^{*}=0,72$ - рис. 2, б).

На рис. 4 показані амплітудно-частотні характеристики

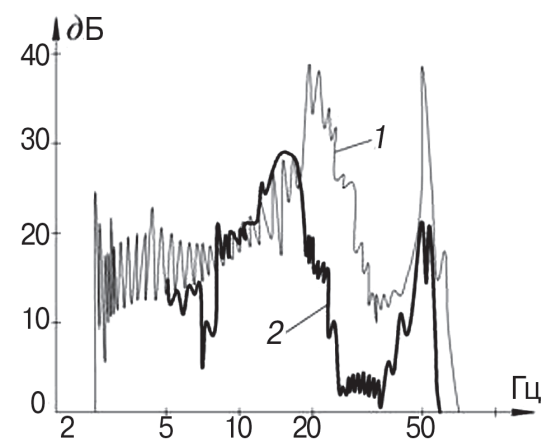

Рис. 4. Амплітудно-частотні характеристики змінної складової сумарної сили, що передається на основу балки мостового крану: 1 - у пасивній системі амортизації; 2 - у АВС з МС управління демпфуванням змінної складової сумарної сили, що передається на основу однієї з керованих опор експериментальної моделі АВС пружної балки мостового крану (рис. 1). Крива 1 відповідає увімкненим, а крива 2 - вимкненим каналам МС управління описаної схеми широкосмугової АВС з керованим демпфуванням. Параметри керування обирались за методикою, викладеною в роботах $[3,5]$. Використане самозбудження $\mathrm{ABC}$ було виключене шляхом рознесення резонансних частот каналу MC управління та балки. Аналіз графіків (рис. 4) показує, що сумісне використання принципів компенсації та керованого демпфування дозволяє забезпечити ефективний віброзахист у широкій смузі частот і забезпечити додатково значне зниження віброактивності на резонансних частотах власних коливань балки мостового крану.

\section{Висновки}

1. Проведений всебічний аналіз стійкості активної віброзахисної системи з мехатронною системою управління демпфуванням коливань (власних) балки мостового крану. 
2. Показано суттєве зменшення величини змінної складової сумарної сили, яка передається на основу крану у результаті використання активної віброзахисної системи порівняно $з$ пасивною системою амортизації.

3. Отримані у роботі результати можуть бути у подальшому використані для вдосконалення існуючих автоматичних віброзахисних систем 3 мехатронними управлінськими блоками, які керують демпфуванням власних коливань балок мостових кранів та суттєво підвищують тим самим надійність функціонування кранів у цілому.

1. Коловский М. 3. Автоматическое управление виброзащитными системами / М. 3. Коловский. - М. : Наука, 1976. - 276 с. 2. Генкин М. Д. Методы активного гашения вибраций механизмов / М. Д. Генкин, В. Г. Елезов, В. В. Яблонский. - В кн. : Динамика и акустика машин. - М. : Наука, 1971. - С. 70-88. 3. Генкин М. Д. К вопросу об активной защите с искусственным демпфированием / М. Д. Генкин, С. В. Кравченко, Э. Л. Рымалов, В. В. Яблонский. - В кн. : Вопросы судостроения : Акустика. - Л., 1984. № 19. - С. 87-90. 4. Фролов К. В. Уменьшение амплитуд колебаний путём управляемого изменения параметров / К. В. Фролов // Машиноведение. 1965. - № 3. - С. 38-42. 5. Кравченко С. В. Выбор параметров каналов управления активными виброзащитными системами с искусственным демпфированием / С. В. Кравченко, Э. Л. Рымалов. - В кн. : Вибрационная техника. - М. : МДНТП, 1984. - С. 56-60. 6. Бидерман В. Л. Теория механических колебаний / В. Л. Бидерман. - М. : Высшая школа, 1980. - 408 с. 7. Бессекерский В. А. Теория автоматического управления / В. А. Бессекерский, Е. П. Попов. - М. : Наука, 1972. - 767 с.

1. Kolovskij M. Z. Avtomaticheskoe upravlenie vibrozaschitnjimi sistemami / M. Z. Kolovskij. - M. : Nauka, 1976. - 276 s. 2. Henkin M. D. Metodji aktivnoho hashenija vibratsij mehanizmov / M. D. Henkin, V. H. Elezov, V. V. Jablonskij. - V kn. : Dinamika i akustika mashin. - M. : Nauka, 1971. S. 70-88. 3. Henkin M. D. K voprosu ob aktivnoj zashchite $s$ iskusstnenjim dempfirovaniem / M. D. Henkin, S. V. Kravchenko, Je. L. Rjimalov, V. V. Jablonskij. - V kn. : Voprosji sudostroenija : Akustika. - L., 1984. № 19. - S. 87-90. 4. Frolov K. V. Umen'shenie amplitud kolebanij putjem upravljaemoho izmenenija parametrov / K. V. Frolov // Mashinovedenie. 1965. - \# 3. - S. 38-42. 5. Kravchenko S. V. Vjibor parametrov kanalov upravlenija aktivnjimi vibrozaschitnjimi sistemami $s$ iskusstvennjim dempfirovaniem / S. V. Kravchenko, Je. L. Rjimalov. - V kn. : Vibratsionnaja technika. - M. : MDNTP, 1984. - S. 56-60. 6. Biderman V. L. Teorija mehanicheskih kolebanij / V. L. Biderman. - M. : Vjisshaja shkola, 1980. - 408 s. 7. Bessekerskij V. A. Teorija avtomaticheskoho upravlenija / V. A. Bessekerskij, E. P. Popov. - M. : Nauka, 1972. - 767 s. 